\title{
Mechanism Sharing Order Information on Simple Supply Chains (Manufacturers) in Reducing Schedule Instability and Total Costs
}

\author{
Mochammad Aldy Anwar ${ }^{1}$, Elsa Rosyidah ${ }^{2}$, Agung Purnomo ${ }^{3}$ \\ Departement of Industrial Engineering, Universitas Nahdlatul Ulama, Sidoarjo, Indonesia ${ }^{1}$ \\ Departement of Environmental Engineering, Universitas Nahdlatul Ulama Sidoarjo, \\ Indonesia $^{2}$ \\ Departement of Business Creation, Institut Teknologi Bina Nusantara, Malang, Indonesia ${ }^{3}$
}

$\left\{\right.$ elsarosyidah@gmail. $\left.\operatorname{com}^{2}\right\}$

\begin{abstract}
Instability in production planning (or better known as schedule instability) always occurs, especially in the manufacturing industry. This makes company companies make various efforts to minimize the level of instability. There are several strategies that are generally used to minimize instability schedules, including freezing, safety stock/buffer. In this study, we will try to use an information sharing approach related to orders received by manufacturers to minimize the consequences of instability schedules in a simple supply chain. A simple supply chain system is the focus of this study consisting of one employer and one supplier who share information regarding order orders. This research will be conducted to study a full factorial experiment (full factorial experiment). A variety of different operating conditions are also considered such as the uncertainty of financing, the cost structure, and the inventory policy applied by the company to be the part observed in this study. The results of this study, namely through the existence of information sharing mechanisms through orders received by manufacturers, are able to reduce the level of schedule instability in each entity both manufacturing and supplier. In addition, through information sharing, it is also able to eliminate the transfer of risks that manufacturers often make to suppliers in the production planning section, as well as being able to reduce total costs to manufacturing or supplier entities. Through this research, it is expected to provide an understanding of the manufacturing industry of the importance of sharing information in the supply chain system.
\end{abstract}

Keywords: Manufacturing, Instability, Industry

\section{Introduction}

Instability in production scheduling activities is inevitable, especially in industries engaged in manufacturing. Instability in production scheduling (often known as schedule instability or nervousness schedules) occurs due to scheduling mismatches with actual conditions that occur on the production floor. Companies belonging to the manufacturing industry will try to minimize the consequences of instability schedules which are considered as trigger indicators in the supply chain performance measurement. The general dimensions that are often a 
reference in the measurement of supply chain performance in manufacturing companies include reliability, responsiveness, cost, and asset management efficiency (Supply Chain Council, 2003, quoted in [1]. Therefore, schedule instability issues are still an interesting topic of discussion for researchers or practitioners in the last period [2].

In general, the phenomenon of schedule instability occurs due to several factors, namely the uncertainty of demand, delays in the delivery of raw materials, or internal company factors such as machines that are not working or in repair conditions. Some researchers also identified specific causes of instability schedules including the cost structure, lot sizing method, order release mechanism, planning period length, re-planning frequency, forecasting errors, and product structure complexity [3]. These factors turned out to be able to influence schedule instability on their own or interact with other factors.

There are several strategies commonly used or proposed by researchers to minimize schedule instability, namely a frozen schedule strategy [4], and the use of safety stock / buffering strategies [2], [5]-[7]. This strategy is considered to be quite good at minimizing schedule instability. In the past few years, information sharing, collaboration, and coordination approaches in the supply chain system have become important areas in the strategy of minimizing schedule instability. Sahin and Robinson [6], show the importance of information sharing, collaboration, and coordination to improve the efficiency of companies in the supply chain in the make-to-order environment. How important there is coordination in managing schedule instability, but not many industries use this strategy in overcoming schedule instability. Therefore, this research will focus on using collaboration strategies that are combined with the method of safety stock / buffering in minimizing schedule instability.

There is not much discussion related to the schedule of instability in the supply chain, even though the impact of schedule instability in the supply chain is very large. Pujawan [2] tried to discuss the schedule of instability within the supply chain, in the viewpoint of buyer-supplier relations by paying attention to the level of instability schedule through safety stock strategies. The scope of the instability schedule in the supply chain begins to develop by looking at the relationships of each company in the supply chain. Schedule instability arises because of the influence of buyer, supplier, and also internal operations of the company [3].

When there is a schedule of instability, each company in the supply chain seeks to minimize the impact of cost instability schedule. The case that often occurs is when there is a schedule of instability from the manufacturing side, manufacturing will make efforts to minimize the costs incurred in the manufacturing business process. Unfortunately, when manufacturers decide to minimize costs often do not pay attention to the impacts that occur on suppliers. So that the supplier's business process does not run efficiently as well as the performance of the supply chain system, this is a big weakness that occurs if companies in the supply chain system do not coordinate with each other.

Looking at the many cases that occur in the manufacturing industry in particular, this research will try to see schedule instability problems in the context of the supply chain system, namely the mechanism for sharing information regarding orders received by manufacturers to suppliers in the make-to-order environment. By looking at schedule instability issues in the make-to-order environment, it can lead to diverse demand fluctuations so as to be able to see the exact schedule of instability in the supply chain system. The mechanism carried out in this research is sharing information related to order demand in production scheduling.

To further focus the model on the problems to be studied, a limitation and assumption will be given for this study. The limitation used in this study is that only the integration between manufacturing and supplier entities was observed in this study. While the assumptions used in this study are: 
- Requests in the planning cycle are uncertain and follow a normal distribution

- The request starts in the 2 nd period,

- There is a lead time for 1 day

- Suppliers in fulfilling demand from manufacturers have never experienced delays due to the existence of information sharing mechanisms

\section{Method}

As explained earlier, this study aims to observe the effect of coordination mechanisms on the level of instability schedules and total costs in the supply chain integration system (manufacturing and suppliers). The initial stages of this study focused on determining the products that were used as objects in the study. In this study, taking objects with production planning is limited to calculations at the MPS level. In addition, this study also considered the existence of lead times, and also the safety stock. In this study, the lead time is constant, which is 1 day and for the safety stock, it is assumed for 1 initial period and also the minimum stock policy imposed by the company.

After determining the product used as the object of research, a simulation experiment can then be carried out starting from the manufacturing entity. The simulation starts with generating the actual demand received by the manufacturer in the $\mathrm{T}$ period, then for the $\mathrm{T}+1$ period until the end of the planning horizon demand forecasting has an error rate of actual demand with a certain average and standard deviation according to what was explained previously. For safety stock, it is raised to meet the T period as a backup for lead times. After that, the quantity and period of the order will be calculated as an order projection to the supplier. For example, random generation results from demand predictions that are normally distributed and booking projections can be seen in the following table:

Table 1 MPS Manufacturing Order Projection at $\mathrm{T}=1$

\begin{tabular}{|l|c|c|c|c|c|c|c|c|}
\hline \multirow{2}{*}{ IPS Manufactur (T = l) } & \multicolumn{7}{|c|}{ Periode (T) } \\
\cline { 2 - 10 } & 0 & 1 & 2 & 3 & 4 & $\mathbf{5}$ & 6 & 7 \\
\hline Gross Requirement & & 207 & & \multicolumn{7}{|c|}{} \\
\hline Forecast Manufacturer & & & 223 & 187 & 210 & 192 & 200 & 185 \\
\hline Inventory On Hand & 207 & 0 & 0 & 0 & 0 & 0 & 0 & 0 \\
\hline Nett Requirement & & 0 & 0 & 0 & 0 & 0 & 0 & 0 \\
\hline Planned Order Receipt & & 0 & 223 & 187 & 210 & 192 & 200 & 185 \\
\hline Planned Order Relaase & & 223 & 187 & 210 & 192 & 200 & 185 & 0 \\
\hline
\end{tabular}

It can be seen in the table that the conditions that occur are for safety stock only to fulfill demand in period 1 for the next period until the end of the plan using the order with lot for lot policy and lead time for 1 day. Furthermore, the order projection process will be carried out to suppliers based on the calculation of the quantity and period of orders made by manufacturers. The following can be seen in the table below the ordering mechanism that is carried out by manufacturers at suppliers with coordination 
Table 2 The calculation mechanism for manufacturing orders to suppliers is information sharing

\begin{tabular}{|c|c|c|c|c|c|c|c|c|}
\hline \multirow{2}{*}{ Manufaktur $(T=1)$} & \multicolumn{8}{|c|}{ Periode (T) } \\
\hline & 0 & 1 & 2 & 3 & 4 & 5 & 6 & 7 \\
\hline Gross Requirement & & 207 & 223 & 187 & 210 & 192 & 200 & 185 \\
\hline Inventory On Hand & 207 & 0 & 0 & 0 & 0 & 0 & 0 & 0 \\
\hline Nett Requirement & & 0 & 0 & 0 & 0 & 0 & 0 & 0 \\
\hline Planned Order Receipt & & 0 & 223 & 187 & 210 & 192 & 200 & 185 \\
\hline Planned Order Release & & 223 & 187 & 210 & 192 & 200 & 185 & 0 \\
\hline \multicolumn{9}{|l|}{ PEMASOK } \\
\hline \multicolumn{9}{|l|}{ Pemasok $(T=1)$} \\
\hline & & & & & & & & 6 \\
\hline Gross Requirement & & $2 \sqrt{3}$ & 187 & $2 \%$ & $19 \sqrt{2}$ & $2 \sqrt{0}$ & 185 & 0 \\
\hline Inventory On Hand & 223 & 0 & 0 & 0 & 0 & 0 & 0 & 0 \\
\hline Nett Requirement & & 0 & 187 & 210 & 192 & 200 & 185 & 0 \\
\hline
\end{tabular}

Furthermore, the same mechanism is carried out to obtain a plan of needs and order projections for suppliers for the $T+1$ period $(T=2)$. The plan description and ordering projections for suppliers can be seen in the following table:

Table 3 Mechanism for calculating manufacturing orders to suppliers $(\mathrm{T}=2)$

\begin{tabular}{|c|c|c|c|c|c|c|c|c|}
\hline \multirow{2}{*}{ Manufaktur $(\mathrm{T}=2)$} & \multicolumn{8}{|c|}{ Periode (T) } \\
\hline & 0 & 1 & 2 & 3 & 4 & 5 & 6 & 7 \\
\hline Gross Requirement & & 198 & 216 & 202 & 206 & 183 & 192 & 193 \\
\hline Inventory On Hand & 198 & 0 & 0 & 0 & 0 & 0 & 0 & 0 \\
\hline Nett Requirement & & 0 & 0 & 0 & 0 & 0 & 0 & 0 \\
\hline Planned Order Receipt & & 0 & 216 & 202 & 206 & 183 & 192 & 193 \\
\hline Planned Order Release & & 216 & 202 & 206 & 183 & 192 & 183 & 0 \\
\hline \multicolumn{9}{|l|}{ PEMASOK } \\
\hline \multicolumn{9}{|l|}{ Pemasok ( $\mathrm{T}=\mathbf{2})$} \\
\hline Gross Requirement & & $\frac{1}{21}$ & $2 \sqrt{2}$ & $2 \sqrt{6}$ & 183 & $1 / \sqrt{2}$ & $\frac{18}{183}$ & $\frac{6}{0}$ \\
\hline Inventory On Hand & 216 & 0 & 0 & 0 & 0 & 0 & 0 & 0 \\
\hline Nett Requirement & & 0 & 202 & 206 & 183 & 192 & 183 & 0 \\
\hline
\end{tabular}

Table 4 Manufacturing order summary to period suppliers $\mathrm{T}=1$ and $\mathrm{T}=2$

\begin{tabular}{|l|c|c|c|c|c|c|c|}
\hline \multirow{2}{*}{ Rencana Pemesanan } & & \multicolumn{6}{|c|}{ Periode (T) } \\
\cline { 2 - 8 } & $\mathbf{1}$ & $\mathbf{2}$ & $\mathbf{3}$ & $\mathbf{4}$ & $\mathbf{5}$ & $\mathbf{6}$ & $\mathbf{7}$ \\
\hline MPS (T=1) & 223 & 187 & 210 & 192 & 200 & 185 & 0 \\
\hline MPS (T=2) & 216 & 202 & 206 & 183 & 192 & 183 & 0 \\
\hline
\end{tabular}

From the summary in the table above, it is clear that there are differences in the quantity of order quantity between periods $\mathrm{T}=1$ and $\mathrm{T}=2$. This is what can cause instability in production scheduling activities, both in manufacturing and suppliers. As explained in the previous chapter, the schedule instability is not only related to changes in order quantity, a shift in the order period also occurs after a recalculation of the plan needs in the new period. However, this study only focuses on instability schedules related to changes in order quantity. 


\section{Result and discussions}

\subsection{Schedule Instability}

The results of schedule instability performance measures are in the form of instability level values. The greater the value of schedule instability, the higher the level of schedule instability. The parameters used for this performance are based on the TM level (Manufacturing TBO), demand variability, and standard deviation from the manufacturing forecast.

Table 5 Schedule instability values for manufacturing under coordination conditions

\begin{tabular}{|c|c|c|c|c|}
\hline TBO & \multicolumn{2}{|c|}{ CV = 0.1 } & \multicolumn{2}{c|}{ CV = 0.4 } \\
\hline Tm & STD =0.1 & STD $=0.4$ & STD $=\mathbf{0 . 1}$ & STD $=0.4$ \\
\hline 1 & 1,0344 & 1,0719 & 1,1066 & 1,0476 \\
\hline 3 & 1,0322 & 1,1233 & 1,0946 & 1,0819 \\
\hline
\end{tabular}

Table 6 Instability schedule values for suppliers under coordination conditions

\begin{tabular}{|c|c|c|c|c|}
\hline TB0 & \multicolumn{2}{|c|}{ CV = 0.1 } & \multicolumn{2}{c|}{ CV =0.4 } \\
\hline Tm & STD =0.1 & STD $=0.4$ & STD $=0.1$ & STD $=0.4$ \\
\hline 1 & 0,0465 & 0,1589 & 0,0446 & 0,1467 \\
\hline 3 & 0,0250 & 0,0941 & 0,0263 & 0,0999 \\
\hline
\end{tabular}

Based on the experimental results that have been shown there are some interesting things related to the performance schedule. First, it can be seen that the existence of a coordination mechanism used by providing information relating to ordering requests is able to reduce the percentage of instability schedules between manufacturers and suppliers in the supply chain system section. In addition, the existence of a parameter of the cost structure that was carried out apparently also had a positive impact on the decrease in the percentage of schedule instability. It can be seen, the greater the value of TBO (TM), there is a significant decrease in the performance schedule.

This is inversely proportional to the condition of absence of coordination, where concern instability that occurs in the supplier entity is quite high due to the absence of coordination between manufacturers and suppliers. It is indeed realized that in the absence of coordination, suppliers will conduct their own forecasting so that there will be a devolution of instability on the supplier side. That is clearly seen in the following table:

Table 7 The value of schedule instability for manufacturing under conditions of no coordination

\begin{tabular}{|c|c|c|c|c|c|c|c|c|c|}
\hline \multirow{2}{*}{\multicolumn{2}{|c|}{ TBO }} & \multicolumn{4}{|c|}{$\mathrm{CV}=0.1$} & \multicolumn{4}{|c|}{$\mathrm{CV}=0.4$} \\
\hline & & \multicolumn{2}{|c|}{ STDM $=0.1$} & \multicolumn{2}{|c|}{ STDM $=0.4$} & \multicolumn{2}{|c|}{ STDM $=0.1$} & \multicolumn{2}{|c|}{ STDM $=0.4$} \\
\hline & & STDP $=$ & STDP $=$ & STDP $=$ & STDP $=$ & STDP $=$ & STDP $=$ & STDP $=$ & STDP $=$ \\
\hline Im & Is & 0.1 & 0.4 & 0.1 & 0.4 & 0.1 & 0.4 & 0.1 & 0.4 \\
\hline T & 2 & 0,0767 & 0,0721 & 0,0702 & 0,0769 & 0,0761 & 0,0768 & 0,2110 & 0,1877 \\
\hline 3 & 2 & 0,0410 & 0,0425 & 0,0435 & 0,0400 & 0,0456 & $0,045 !$ & 0,1125 & 0,1321 \\
\hline$T$ & 4 & 0,0754 & 0,0804 & 0.0758 & 0,0776 & 0.0749 & 0,0762 & 0.2053 & 0,2048 \\
\hline 3 & 4 & $0,040 !$ & 0,0375 & 0,0458 & 0,0498 & 0,0405 & 0,0448 & $0,134 !$ & 0,1208 \\
\hline
\end{tabular}


Table 8 The instability schedule value for suppliers under conditions of no coordination

\begin{tabular}{|c|c|c|c|c|c|c|c|c|c|}
\hline \multirow{2}{*}{\multicolumn{2}{|c|}{ TBO }} & \multicolumn{4}{|c|}{$\mathrm{CV}=0.1$} & \multicolumn{4}{|c|}{$\mathrm{CV}=0.4$} \\
\hline & & \multicolumn{2}{|c|}{ STDM $=0.1$} & \multicolumn{2}{|c|}{ STDM $=0.4$} & \multicolumn{2}{|c|}{ STDM = 0.1 } & \multicolumn{2}{|c|}{ STDM $=0.4$} \\
\hline $\mathrm{Tm}$ & Is & $\begin{array}{c}\text { STDP }= \\
0.1\end{array}$ & $\begin{array}{c}\text { STDP }= \\
0.4\end{array}$ & $\begin{array}{c}\text { STDP }= \\
0.1\end{array}$ & $\begin{array}{c}\text { STDP }= \\
0.4\end{array}$ & $\begin{array}{c}\text { STDP }= \\
0.1\end{array}$ & $\begin{array}{c}\text { STDP }= \\
0.4\end{array}$ & $\begin{array}{c}\text { STDP }= \\
0.1\end{array}$ & $\begin{array}{c}\text { STDP }= \\
0.4\end{array}$ \\
\hline 1 & 2 & 0,1126 & 0,2290 & 0,1156 & 0,2265 & 0,1143 & 0,1732 & 0,1051 & 0,2136 \\
\hline 3 & 2 & 0,0847 & 0,1797 & 0,0942 & 0,1634 & 0,0957 & 0,1400 & 0,1083 & 0,2057 \\
\hline 1 & 4 & 0,1061 & 0,2173 & 0,1189 & 0,2155 & 0,1151 & 0,1721 & 0,1071 & 0,2260 \\
\hline 3 & 4 & 0,0878 & 0,1731 & 0,0891 & 0,1695 & 0,0954 & 0,1529 & 0,1074 & 0,2146 \\
\hline
\end{tabular}

In the results of the simulations that have been conducted, it is seen that there is a significant increase in the supplier side when there is no coordination mechanism. The use of a cost structure that is the value of TBO in manufacturing (TM) is also not able to minimize the increase in the percentage value of schedule instability. the influence of the mechanism is very significant for the decline in the value of instability in each entity both manufacturing, supplier, and the overall supply chain system.

\subsection{Total Cost}

Related to the cost elements calculated in this study are based on two general cost elements, which consist of holding costs, and setup/order costs. These two elements of cost are considered quite representative because these cost elements are commonly used by companies. In the position of the two-stage supply chain integration system with coordination, there is a decrease in the total cost of the supplier entity. The position of the costs of each entity in a coordinated position can be seen in the following figure:

Figure 1 Amount of Total Cost Value for manufacturers and suppliers in different supply chain systems

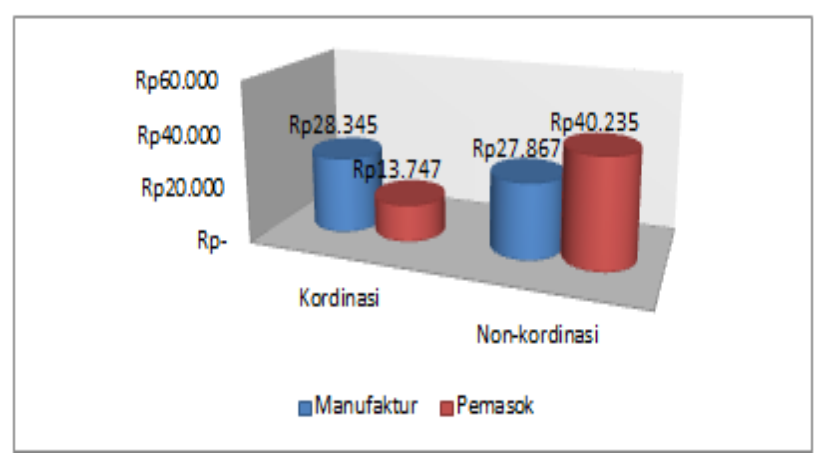

Seen in figure 1 the position of the integration system (two-stage) with the coordination in the supply chain system can reduce costs incurred by the supplier entity by up to $51 \%$. On the other hand, in the supply chain system without coordination, the suppliers bear greater costs until the cost difference almost increases by $30 \%$. This indicates that in the supply chain system each entity seeks to minimize costs, but when there is no coordination, for example, manufacturing policies that minimize the cost of securities are at the upstream level or in this 
study, suppliers will be affected by unexpected cost increases. As is known that production orders are always controlled by variability and uncertainty in demand. Therefore, there needs to be coordination in the supply chain system in reducing costs incurred.

\section{Conclusion}

Based on the experiment and the results of data processing and analysis that have been carried out, there are several conclusion points in this study namely:

- Variability in consumer demand and uncertainty in manufacturing forecasting have a positive impact on the level of schedule instability;

- Information sharing mechanism can reduce the level of instability in each entity in the supply chain system;

- The use of information sharing mechanisms, the existence of a cost structure, and safety stock policies that are able to reduce instability have an impact on the total costs incurred for each entity to decrease. Element of the reduced cost for each entity, namely the accumulation of the ordering costs and inventory costs.

\section{References}

[1] M. J. Meixell, "The impact of setup costs, commonality, and capacity on schedule stability: An exploratory study,” Int. J. Prod. Econ., vol. 95, no. 1, pp. 95-107, Jan. 2005.

[2] I. N. Pujawan, "Schedule Instability in a Supply Chain: An Experimental Study," Int. J. Invent. Res., vol. 1, no. 1, 2008.

[3] I. N. Pujawan, Smart, and A. U, "Factors Affecting Schedule Instability in Manufacturing Companies," Int. J. Prod. Res., vol. 50, no. 8, 2012.

[4] X. Zhao and T. S. Lee, "Freezing the master production schedule for material requirements planning systems under demand uncertainty," J. Oper. Manag., vol. 11, no. 2, pp. 185-205, Jun. 1993.

[5] J. Xie, X. Zhao, and T. S. Lee, "Freezing the master production schedule under single resource constraint and demand uncertainty," Int. J. Prod. Econ., vol. 83, no. 1, pp. 65-84, Jan. 2003.

[6] F. Sahin and E. P. Robinson, "Flow Coordination and Information Sharing in Supply Chains: Review, Implications, and Directions for Future Research," Decis. Sci., vol. 33, no. 4, pp. 505-536, Sep. 2002.

[7] V. Sridharan and R. L. LaForge, "The Impact of Safety Stock on Schedule Instability, Cost and Service," J. Oper. Manag., vol. 8, no. 4, pp. 327-347, 1989. 